\title{
Impact on COVID-19 hospitalisation rates of Maltese elderly following achievement of $70 \%$ first dose vaccine coverage.
}

\author{
Michael Borg ${ }^{1}$, David Suda ${ }^{2}$, Andre Brincat ${ }^{3}$, Steve Agius $^{3}$, and Christopher Fearne ${ }^{3}$ \\ ${ }^{1}$ University of Malta Medical School \\ ${ }^{2}$ University of Malta \\ ${ }^{3}$ Mater Dei Hospital
}

August 22, 2021

\begin{abstract}
We studied COVID-19 hospitalisation rates in elderly Maltese residents, aged 80 years and older, after national attainment of $70 \%$ first-dose coverage of COVID-19 vaccine in this age cohort. The milestone resulted in almost $50 \%$ reduction of hospital admissions, as confirmed by time series modelling using national SARS-CoV-2 infection rates as the comparator. The reduction was not seen in younger, as yet unvaccinated, age groups, where hospital admissions actually increased during the same period following a third wave of infections.
\end{abstract}

\section{Hosted file}

Manuscript text.docx available at https://authorea.com/users/431351/articles/534838-impacton-covid-19-hospitalisation-rates-of-maltese-elderly-following-achievement-of-70-firstdose-vaccine-coverage

\section{Hosted file}

Table.docx available at https://authorea.com/users/431351/articles/534838-impact-on-covid19-hospitalisation-rates-of-maltese-elderly-following-achievement-of-70-first-dosevaccine-coverage

\section{Hosted file}

Figures.docx available at https://authorea.com/users/431351/articles/534838-impact-on-covid19-hospitalisation-rates-of-maltese-elderly-following-achievement-of-70-first-dosevaccine-coverage 